\title{
An instrument for assessment of videotapes of general practitioners' performance
}

\author{
Jim Cox, Helen Mulholland
}

\begin{abstract}
Objectives-To identify those important characteristics of doctors' and patients' behaviour that distinguish between "good" and "bad" consultations when viewed on videotape; to use these characteristics to develop a reliable instrument for assessing general practitioners' performance in their own consultations.
\end{abstract}

Design-Questionnaires completed by patients, general practitioner trainers, and general practitioner trainees. Reliability of draft instrument tested by general practitioner trainers.

Setting-All vocational training schemes for general practice in the Northern region of England.

Subjects-First stage: $\mathbf{7 6}$ patients in seven groups, 108 general practice trainers in 12 groups, and 122 general practice trainees in 10 groups. Second stage: 85 general practice trainers in 12 groups.

Main outcome measures-Trainers' ratings of importance; $\alpha$ coefficients of draft instrument by trainee, group, and consultation.

Results -6890 characteristics of good and bad consultations were consolidated into a draft assessment instrument consisting of 46 pairs of definitions separated by six point bipolar scales. Nine statement pairs given low importance ratings by trainers were eliminated, reducing the instrument to 37 statement pairs. To test reliability, general practitioner trainers used the instrument to assess three consultations. With the exception of one group of trainers, all $\alpha$ coefficients exceeded the acceptable level of $0 \cdot 80$.

Conclusion-The instrument produced is reliable for assessing general practitioners' performance in their own consultations.

\section{Introduction}

Assessment in medical education is an integral part of the "educational triangle" of aims, methods, and assessment. ' Once a trainee's strengths and weaknesses have been identified, training can be focused on his or her individual needs. On completion of training the trainee, the teachers, and society should know that an acceptable standard of competence has been reached.

In general practice in the United Kingdom there is agreement that regular formative assessment using a variety of methods to measure different trainee attributes is a necessary part of the educational process. Since January 1993 assessment has been mandatory. ${ }^{2}$

Existing methods of assessment such as written papers, oral examinations, long and short cases, and objective structured clinical examinations have inbuilt problems of validity. Although it is important to know what candidates can do, it is equally or more important to know what they actually do. ${ }^{3}$ The relation between what a doctor is capable of doing (competence) and what he or she does in practice (performance) is tenuous. ${ }^{48}$ There is considerable interest in the use of objective structured clinical examinations and simulated, standardised patients in assessment, ${ }^{9-13}$ but it is not easy to ensure that simulated patients behave consistently in consultations with different candidates. ${ }^{14} 15$

Encounters with simulated patients also require the doctor and patient to establish a new relationship and deal with a problem for the first time. In reality, however, many general practice consultations are part of a longer term relationship in which, for example, diagnoses and management plans emerge over series of encounters. We attempted to improve validity by looking at the doctor's actual performance in real life consultations, including those with patients already known to the doctor.

Analysis of videotaped consultations is widely used in medical education in many disciplines. ${ }^{1617}$ Methods include "mapping" of consultations, in which observers describe the processes of problem definition, taking action, etc, ${ }^{18}$ or more general judgments about the interaction between doctor and patient, including attitudes such as the trainee's confidence. ${ }^{19}$ However, a valid, reliable, and feasible method for measuring a general practitioner's performance by using videotape is not yet available. The purpose of this study was to develop such an instrument, which could be used together with other assessment methods that test different attributes such as knowledge and problem solving ${ }^{20}$ to produce an overall profile ${ }^{21}$ of a candidate's competence and performance.

To develop an assessment instrument one must first decide what attributes should be measured..$^{22}{ }^{23}$ There are many attributes of a competent general practitioner, ${ }^{24} 25$ not all of which can be tested by one type of test. We started from basic principles and asked patients, experienced general practitioners, and trainees to identify the important characteristics of "good" and "bad" general practitioners which could be assessed through videotaped consultations.

\section{Methods}

The study was carried out in two stages: constructing the instrument and validating it.

\section{CONSTRUCTING THE INSTRUMENT}

All general practice trainers in the Northern region are members of trainer groups that meet regularly. Trainees also meet regularly for the "academic" part of their vocational training courses. One meeting of each of the 12 trainer groups and 10 trainee groups was dedicated to the first stage of the study. Participants were asked to identify those important characteristics of doctor and patient behaviour that distinguish between good and bad consultations when viewed on video.
Dr Jim Cox, The Surgery, Caldbeck, Wigton, Cumbria CA7 8DS. 


\section{Instrument for assessing videotapes of doctors' performance in consultations}

Markers circle the vertical line on each scale that most closely describes agreement with the statements at each end of the scale. If they have insufficient information to give a mark they write $\mathrm{X}$ in the box.

The doctor concentrates on records / computer / or elsewhere than the patient / avoids eye contact

The doctor is relaxed / tolerant

The patient is not involved in decision making

The doctor is cold / distant / frightening / unfriendly / abrupt / sarcastic

The doctor explains diagnosis/ management / side effects of treatment The doctor is discreet / respects confidentiality

The doctor makes an appropriate physical examination when necessary

The doctor is knowledgable / up to date

The doctor is authoritarian / patronising / judgmental / moralising / pompous / condescending

The doctor is honest

The doctor's diagnosis and managemen appear to be sensible / safe / helpful / correct / considers alternatives

Follow up arrangements are inadequate / unnecessary / unclear

The doctor prescribes prematurely / inappropriately

The doctor wastes time

The doctor answers questions

The doctor considers patient and family history / background

The doctor is not courteous

At the end of the consultation the patien appears unnecessarily angry / irritated / unhappy / complains

The doctor allows patient opportunity to discuss other problems

The doctor is reassuring / encouraging / decisive / inspires confidence

The doctor ends the consultation well

The doctor explores patient's ideas / concerns / expectations

The doctor ignores continuing problems

Investigations are neglected / illogical / unjustifiable

The doctor is empathetic

The doctor uses inappropriate language medical jargon / swamps patient with information

The doctor listens to the patient / looks interested

The doctor's approach is thorough

The doctor is thoughtless / unkind / uncaring

The doctor misses or misinterprets cues clues / body language / hidden agend The doctor gives appropriate advice

The doctor allows time for the patient

The doctor makes unnecessary or inappropriate referrals or fails to refer when necessary

Allowing for the nature of the consultation the patient appears to be as relaxed / at ease as possible

The doctor is confused / contradictory / disorganised / dithers / fumbles

The doctor interrupts the patien unnecessarily

The doctor takes an adequate and appropriate history from the patient

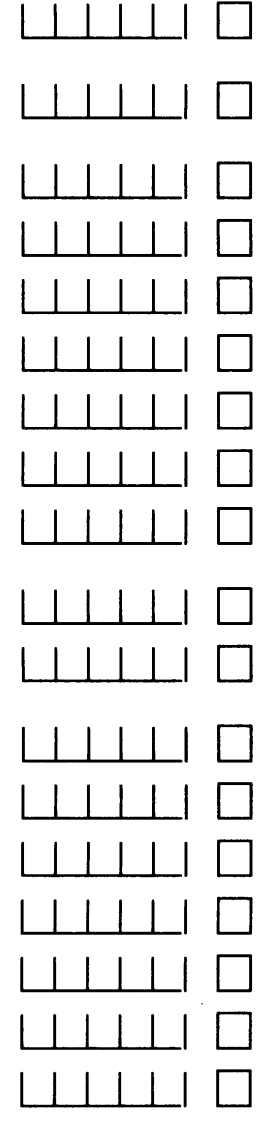

There is eye contact between doctor and patient most of the time

The doctor is tense / uncomfortable / impatient / irritated / rude / loses temper / has irritating habits

The patient is involved in decision making

The doctor smiles / is warm / friendly / pleasant / touches patient when appropriate

The doctor does not explain diagnosis / management / side effects of treatment

The doctor breaches confidentiality

Physical examination of the patient is inadequate / examination inappropriate

The doctor lacks up to date knowledge

The doctor is humble / approachable / flexible / treats the patient as an equal

The doctor is dishonest / evasive / insincere / oversincere

The doctors diagnosis and management are irrational / unjustified / dangerous

The doctor arranges appropriate follow up

The doctor prescribes appropriately

The doctor uses time efficiently

The doctor ignores or evades questions

The doctor makes incorrect assumptions / umps to conclusions

The doctor is courteous

Allowing for the nature of the consultation the patient appears satisfied at the end

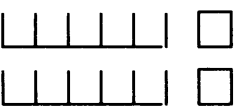

11110 The end of the consultation is rude / prolonged / abrupt

The doctor ignores the patient's ideas / concerns / expectations / fails to recognise reason for consultation

The doctor inquires about and manages continuing problems

If necessary, the doctor undertakes appropriate investigations $/ x$ rays, etc The doctor disregards / dismisses / trivialises patient's views / feelings

The patient understands the doctor

$\begin{array}{llll}1 & 1 & 1\end{array}$ The doctor ignores the patient / talks too much / is offhand / aloof / uninterested / bored

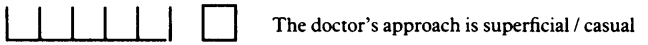

\begin{tabular}{ll|l|l|}
\hline & $\mid$ & $\mid$ & $\square$
\end{tabular} The doctor is caring / kind

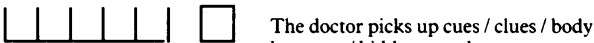
The doctor picks up cues
language / hidden agenda

The doctor gives inappropriate / impractical advice or fails to respond to verbal or nonverbal request for advice

The consultation is hurried / rushed

If necessary, the doctor makes an appropriate referral (within or without the practice)

The patient appears unnecessarily uncomfortable / confused / dissatisfied uncomfortable / confused

The consultation is logical / well organised

The doctor does not interrupt the patient inappropriately

The history taken is inadequate / inappropriate / irrelevant / disorganised
Organisers of patient groups in a range of urban, rural, and geographically mixed practices were selected to reflect the region as a whole. Organisers were asked to invite a group of about 12 patients including a range of age (from 16 upwards), sex, and social class in proportion to their practice population.

Definitions of "good" and "bad" were deliberately left open to encourage participants to generate ideas. Participants were given the following information:

We are trying to find out what you think are the most important characteristics of a good general practice consultation and what are the features of a bad consultation.

We are interested only in assessing the doctors' conduct of the consultation-not other aspects of the practice such as organisation, decor, and staff.

Please make two lists-not necessarily in order of importance. Firstly, list the things about the doctor that you think are good (in the left hand column) then list the things you think are "bad" in the right hand column.

The principles of ethnography, a qualitative research method used in sociological studies to understand behaviour, ${ }^{2627}$ were used to consolidate 6890 responses into a draft assessment instrument containing 46 statement pairs of good and bad characteristics. Essentially, the method requires the researcher to focus on findings or events that do not fit into existing concepts (breakdowns) and repeatedly resynthesise the concepts until breakdowns are eliminated and a coherent account that accommodates them has been achieved.

The resulting draft assessment instrument consisted of 46 pairs of descriptive adjectives that defined extreme good and bad characteristics. Each pair was attached to a six point bipolar rating scale. An even number of divisions was used so that respondents could not choose the midpoint but must make a decision.

\section{VALIDATION AND RELIABILITY TESTING}

On the premise that the instrument is to be used by professional general practice educators, the second stage - validation-was confined to general practice trainers. At a second meeting, each trainer group member was asked to score the importance of each statement pair in the draft instrument on a scale from 0 (of no importance at all) to 5 (extremely important), to propose any additional items that should have been included, and to suggest any other modifications to the instrument.

We eliminated statement pairs with a mean score of less than 3.5 from the questionnaire. The remaining statement pairs were randomised in two ways: good and bad characteristics were randomly allocated to the left or right hand ends of the scales and the order of statement pairs was randomised so that the characteristics to be assessed were not arranged in sequence.

We tested the reliability for each statement pair by asking each trainer to use the draft instrument to assess videotapes of three trainee consultations at the second group meeting. We selected consultations to reflect a variety of patients by age and sex and to include patients known and not known to the doctor. Each group of trainers watched two consultations by one trainee and a third by a different trainee. Between 13 and 26 markers scored each consultation.

By systematically assigning different consultations to different groups it was possible to calculate reliability of scores for each trainee, for each consultation, and between markers within each group. The measure of reliability used was the $\alpha$ coefficient, a measure of the degree of consistency within a test. ${ }^{28}$ The higher the value, the greater the reliability; an acceptable value is $0 \cdot 80 . .^{29}$ 
Results

INSTRUMENT CONSTRUCTION

A total of 6890 (5585 individual and 1305 group) responses were derived from 29 groups, of which 3829 $(55.6 \%)$ responses were good characteristics and 3061 $(44.4 \%)$ bad. Table I shows the composition of the groups. Although trainer and trainee groups were representative of the region as a whole, patient groups tended towards older, female participants.

More than $90 \%$ of responses could be incorporated into statement pairs. Table II shows the 10 statement pairs supported by most individuals and groups.

The only statement pair supported by more trainees than trainers concerned the importance of humility, approachability, flexibility, and treating the patient as an equal. Conversely, trainers more than trainees emphasised the importance of time management, physical examination, investigations, diagnoses, management, and follow up arrangements.

There was considerable agreement between doctors and patients that good doctors listen to their patients and that bad doctors ignore them, that good doctors allow time for their patients whereas bad doctors hurry or rush, and that good doctors explain the diagnosis, management, and side effects of treatment whereas bad doctors do not.

VALIDATION AND RELIABILITY TESTING

Eighty five (54\%) of the region's 156 trainers met for a second time. Table III shows their importance scores for each statement pair. The mean rating of 37 of the 46 statement pairs was greater than 3.5 . The nine statement pairs with a mean rating of less than 3.5 were eliminated from the instrument.

No additional items were proposed. Several trainers suggested rewording of statements but there were no consistent comments so we did not make any changes.

TABLE I-Instrument construction: composition of groups and numbers of responses

\begin{tabular}{lccc}
\hline & Trainers & Trainees & Patients \\
\hline No of groups & 12 & 10 & 7 \\
No of participants & 108 & 122 & 76 \\
No (\%) in region & $156(69)$ & $269(45)$ & \\
Mean (range) group size & $9 \cdot 1(4-13)$ & $12 \cdot 2(8-17)$ & $10 \cdot 8(6-13)$ \\
Mean (range) age (years) & $41(30-64)$ & $28(23-53)$ & $50(17-79)$ \\
Male:female ratio & $88: 10$ & $64: 47$ & $26: 48$ \\
No (\%) with age or sex not given & $10(10)$ & $11(9)$ & $2(3)$ \\
No of responses: & & & \\
"Good" individual responses & 1307 & 1307 & 498 \\
"Bad" individual responses & 1169 & 962 & 342 \\
"Good" group responses & 334 & 260 & 123 \\
"Bad" group responses & 285 & 207 & 96 \\
\hline Total responses & 3095 & 2736 & 1059 \\
Mean responses per participant & $28 \cdot 6$ & $27 \cdot 4$ & $13 \cdot 9$ \\
\end{tabular}

TABLE II-Statement pairs most often volunteered as distinguishing "good" and "bad" doctors

\begin{tabular}{|c|c|c|c|}
\hline & Statement pair & $\begin{array}{l}\text { No }(\%) \text { of } \\
\text { individuals }\end{array}$ & $\begin{array}{l}\text { No (\%) of } \\
\text { groups }\end{array}$ \\
\hline 1 & $\begin{array}{l}\text { The doctor listens to the patient/looks interested. } \\
\text { The doctor ignores the patient/talks too much/is offhand/aloof/uninterested/bored. }\end{array}$ & $252(82)$ & $27(93)$ \\
\hline 2 & $\begin{array}{l}\text { There is eye contact between the doctor and patient most of the time. } \\
\text { The doctor concentrates on records/computer/elsewhere than the patient/avoids eye } \\
\text { contact. }\end{array}$ & $196(64)$ & $29(100)$ \\
\hline 3 & $\begin{array}{l}\text { The doctor explains diagnosis/management/side effects of treatment. } \\
\text { The doctor does not explain diagnosis/management/side effects of treatment. }\end{array}$ & $186(61)$ & $28(96)$ \\
\hline 4 & $\begin{array}{l}\text { The doctor allows time for the patient. } \\
\text { The consultation is hurried/rushed. }\end{array}$ & $176(57)$ & $24(83)$ \\
\hline 5 & $\begin{array}{l}\text { The doctor is empathetic. } \\
\text { The doctor disregards/dismisses/trivialises the patient's views/feelings. }\end{array}$ & $176(57)$ & $22(76)$ \\
\hline 6 & $\begin{array}{l}\text { The doctor smiles/is warm/friendly/pleasant/touches the patient when appropriate. } \\
\text { The doctor is cold/distant/frightening/unfriendly/abrupt/sarcastic. }\end{array}$ & $167(54)$ & $23(79)$ \\
\hline 7 & $\begin{array}{l}\text { The doctor is humble/approachable/flexible/treats the patient as an equal. } \\
\text { The doctor is authoritarian/patronising/judgmental/moralising/pompous/ } \\
\text { condescending. }\end{array}$ & $142(46)$ & $24(83)$ \\
\hline 8 & $\begin{array}{l}\text { The doctor is reassuring/encouraging/decisive/inspires confidence. } \\
\text { The doctor fails to reassure the patient or inspire confidence/indecisive/overconfident. }\end{array}$ & $140(46)$ & $25(86)$ \\
\hline 9 & $\begin{array}{l}\text { The doctor is relaxed/tolerant. } \\
\text { The doctor is tense/uncomfortable/impatient/irritated/rude/loses temper/has irritating } \\
\text { habits. }\end{array}$ & $136(44)$ & $21(72)$ \\
\hline 10 & $\begin{array}{l}\text { The patient is involved in decision making. } \\
\text { The patient is not involved in decision making. }\end{array}$ & $132(43)$ & $24(83)$ \\
\hline
\end{tabular}

TABLE III-Mean importance ratings for statement pairs

\begin{tabular}{|c|c|c|}
\hline Mean (scale 0-5) & Frequency & Cumulative frequency \\
\hline $2 \cdot 5-$ & 2 & 2 \\
\hline $3 \cdot 0-$ & 7 & 9 \\
\hline $3 \cdot 5-$ & 11 & 20 \\
\hline $4 \cdot 0-$ & 24 & 44 \\
\hline $4 \cdot 5-5 \cdot 0$ & 2 & 46 \\
\hline \multicolumn{3}{|c|}{ TABLE IV-Reliability analysis (individual statement pairs) } \\
\hline & & $\alpha$ Coefficient \\
\hline \multicolumn{3}{|l|}{ Trainee No: } \\
\hline 1 & & 0.89 \\
\hline 2 & & 0.88 \\
\hline 3 & & $0 \cdot 88$ \\
\hline 4 & & 0.92 \\
\hline 5 & & 0.95 \\
\hline 6 & & 0.90 \\
\hline \multicolumn{3}{|c|}{ Group No (No in group): } \\
\hline $1(7)$ & & 0.91 \\
\hline $2(8)$ & & 0.85 \\
\hline $3(9)$ & & 0.91 \\
\hline $4(9)$ & & 0.93 \\
\hline $5(8)$ & & $0 \cdot 84$ \\
\hline $6(6)$ & & 0.95 \\
\hline $7(8)$ & & 0.92 \\
\hline $8(4)$ & & 0.96 \\
\hline $9(9)$ & & 0.91 \\
\hline $10(3)$ & & $0 \cdot 79$ \\
\hline $11(6)$ & & 0.96 \\
\hline $12(8)$ & & 0.91 \\
\hline \multicolumn{3}{|c|}{ Consultation No (trainee No): } \\
\hline $1(1)$ & & 0.91 \\
\hline $2(1)$ & & 0.85 \\
\hline $3(2)$ & & 0.89 \\
\hline $4(2)$ & & 0.84 \\
\hline $5(3)$ & & 0.90 \\
\hline $6(3)$ & & 0.89 \\
\hline $7(4)$ & & 0.91 \\
\hline $8(4)$ & & 0.88 \\
\hline $9(5)$ & & 0.93 \\
\hline $10(5)$ & & 0.93 \\
\hline $11(6)$ & & 0.91 \\
\hline $12(6)$ & & 0.83 \\
\hline
\end{tabular}

Reliability of scores both by consultation and by trainee was greater than 0.83 for every statement pair and is shown in table IV together with intermarker reliability for each trainer group. With the exception of group 10, which consisted of only three trainers, all the $\alpha$ coefficients exceeded the acceptable level of $0 \cdot 80$.

The final instrument, which consisted of 37 statement pairs separated by a 6 point scale, is shown in the box.

\section{Discussion}

Most descriptions of general practice consultations are still based, at least in part, on the pioneering work of Byrne and Long ${ }^{30}$ who in the early 1970s analysed audiotapes of consultations. They listed behaviours that occurred frequently and described a logical (but rare) sequence of six stages of an "ideal" consultation.

Hays in Australia, ${ }^{19}$ Pendleton et $a l,{ }^{18}$ and Fraser et $a^{31}$ have developed Byrne and Long's model, devising instruments for assessing the process of consultations. These methods are based on descriptions of consultations developed for teaching and learning. The model or "construct" in this study is different. It was specifically developed for the purpose of assessment.

Instead of using existing models of the consultation we went back to basic principles and asked trainers, trainees, and patients to characterise those qualities of a consultation that distinguish between good and bad general practitioners. Thus we established face validity from basic principles. By assessing real life consultations, without the use of simulated, standardised patients, our method bridges the gap between competence and performance.

The doctors and patients who contributed to the study emphasised the importance of doctors' attitudes when distinguishing between good and bad doctors. 
This view is confirmed by the General Medical Council in their proposals for new performance review procedures. ${ }^{32}$

The instrument could be used to assess only those attributes (including doctors' attitudes) that can be seen, heard, or deduced through observation of videotaped consultations. Attributes such as problem solving ability, record keeping, or depth and breadth of knowledge can not be assessed in this way. If an instrument such as ours was, for example, to be used by trainers or other assessors for the summative assessment of trainees at the end of training or of doctors whose standards of performance were in doubt then it would also be necessary to use other assessment methods to obtain a profile of their strengths and weaknesses.

We thank all the patients, trainees, trainers, and course organisers who participated in the study and also Professor John Anderson, Mrs Pat Porter, Dr Donald Irvine, Dr Paul Creighton, Dr George Taylor, and Dr Rodger Thornham.

1 Gray DP. Assessment in general practice. 7 R Coll Gen Pract 1988;38:344-5.

2 Joint Committee on Postgraduate Training for General Practice. Assessmen Working Party. Interim report. London: JCPTGP, 1992.

3 Miller GE, Abrahamson S, Cohen IS, Graser HP, Hamack RS, Land AL Teaching and learning in medical school. Cambridge, Massachusetts: Harvard University Press, 1962

4 Ramsey PG, Carline JD, Inui TS, Larson EB, LoGerfo JP, Wenrich MD. Predictive validity of certification by the American Board of Internal Medicine. Intern Med 1989;110:719-26.

5 Jones TV, Gerrity MS, Earp J. Written case simulations: do they predict physicians' behavior? I Clin Epidemiol 1990;43:805-15.

6 McLeskey CH, Ward RJ. Validity of written examinations. Anesthesiolog 1978;49:224.

7 Brook RA, Williams KN. Evaluation of the New Mexico peer review system 1971 to 1973. Medical Care 1976;14:63-94.

8 Rethans JJ, Sturmans F, Drop R, van der Vleuten C. Assessment of the performance of general practitioners by the use of standardised (simulated) patients. Br f Gen Pract 1991;41:97-9.

9 Harden RM, Gleeson FA. Assessment of medical competence using an objective structured clinical examination (OSCE). Dundee: Association for the Study of Medical Education, 1979. (ASME medical education booklet No 8.)

10 Norman GR, Neufeld VR, Walsh A, Woodward CA, McConvey GA. Measuring physicians' performances by using simulated patients. fournal of Medical Education 1985;60:925-34.
11 Rethans JJE, van Boven CPA. Simulated patients in general practice: a different look at the consultation. $B M 7$ 1987;294:809-12

12 Rethans JJ, Drop R, Sturmans F, van der Vleuten C. A method for introducing standardised (simulated) patients into general practice consultations. Br f Gen Pract 1991;41:94-6.

13 Colliver JA, Vu NV, Markwell SJ, Verhulst SJ. Reliability and efficiency of components of clinical competence assessed with five performance-based examinations using standardised patients. Med Educ 1991;25:303-10.

14 Tamblyn RM, Klass DJ, Schnabl GK, Kopelow ML. The accuracy of standardized patient presentation. Med Educ 1991;25:100-9.

$15 \mathrm{Vu} \mathrm{NV}$, Marcy MM, Colliver JA, Verhulst SJ, Travis TA, Barrows HS Standardised (simulated) patients' accuracy in recording clinical performance check-list items. Med Educ 1992;26:99-104.

16 Rutter DR, Maguire GP. History-taking for medical students: evaluation of training programme. Lancet 1976;ii:558-60.

17 Premi J. An assessment of 15 years' experience in using videotape review in family practice residency. Academic Medicine 1991;66:56-7.

18 Pendleton B, Schofield T, Tate P, Havelock P. The consultation: an approach to learning and teaching. Oxford: Oxford University Press, 1984

19 Hays RB. Assessment of general practice consultations: content validity of rating scale. Med Educ 1990;24:110-6.

20 Lockie C, ed. Examination for membership of the Royal College of General Practitioners: development, current state and future trends. London: Royal College of General Practitioners, 1990. (Occasional paper 46.)

21 Bligh J, Price A. Profiling - a continuing assessment programme. Postgraduate Education for General Practice 1991;2:28-35.

22 Mulholland H. Assessment of competence in general practice. Horizon 1991;5:274-7.

23 Neufeld VR, Norman GR, eds. Assessing clinical competence. New York: Springer, 1985.

24 The future general practitioner: learning and teaching. London: Royal College of General Practitioners, 1972

25 Joint Committee on Postgraduate Training for General Practice. Accreditation of regions and schemes for vocational training in general practice: general guidance. London: JCPTGP, 1992

26 Agar MH. Speaking of ethnography. Beverly Hills: Sage, 1986.

27 Strauss A, Corbin J. Basics of qualitative research: grounded theory procedures and techniques. Newbury Park, California: Sage, 1990

28 Cronbach LJ, Gleeson GC. Dependability of behavioral measurement. New York: Wiley, 1972

29 Van der Vleuten CPM, Swanson DB. Reliability issues in objective structured clinical examinations. In: Hart IR, Harden RM, Des Marchais J, eds. Current developments in assessing clinical competence. Montreal: Can-Heal Publications, 1992.

30 Byme PS, Long BEL Doctors talking to patients. London: HMSO, 1976

31 Fraser RC, McKinley RK, Mulholland H. Assessment of consultation competence in general practice: the Leicester assessment package. In: Harden RM, Hart IR, Mulholland H, eds. Approaches to the assessment of clinical competence part 1. Dundee: Centre for Medical Education, 1992. 192-8

32 Kilpatrick R. Rationale behind the General Medical Council's proposed new procedure for the assessment of doctors' performance. $\mathrm{Br} \mathcal{J}$ Gen Pract 1993;43:2-3.

(Accepted 11 February 1993)

\section{A PATIENT WHO CHANGED MY PRACTICE}

\section{Defining the limits of empathy}

Steve was a policeman in his $30 \mathrm{~s}$, retired on medical grounds because of chronic glomerulonephritis. I got to know him in 1971 as one of the patients on the renal unit at the London Hospital, where I had just been appointed as a lecturer. In the early 1970 s I was an outspoken radical and intent on demonstrating a different approach. A major component was accessibility. I was John and the patients were friends. Steve lived in a council house in suburban Essex and I was invited to meet his wife and his 12 year old son Martin. Like me, Martin was an Arsenal fan, and on a couple of occasions I took him to Highbury.

One morning I came on to the dialysis unit to find Steve ghostly pale and unconscious with a blood transfusion running. The night before he had connected himself up to his home haemodialysis machine, apparently without properly checking the connections, and a line had come apart during the night. It seems that the machine alarm had not worked, either because it, too, had not been checked or because of a mechanical fault. For the next two or three days I was unable to function properly. I was as worried as any relative could be about what would happen. That my anxieties were informed anxieties made me, if anything, more worried rather than less.

Steve did recover, with nothing more than a little retrograde amnesia. When I went to see him he had been discussing with the staff and his wife what might have gone wrong and he was expecting a severe carpeting from me. But I was far too relieved to be cross with him and just said, "Well, I don't suppose you'll do that again, Steve."

I think my practice has changed in two ways. Firstly, I'm much more at arm's length in my involvement with, but I hope not in my sympathy for, patients. It has to be possible to be sympathetic and caring without your patient's problems becoming your problems. I am convinced that any gains that could accrue are far outweighed by the loss of objectivity that we experience when someone we love is ill. Caring practice is the need to walk a tightrope, being neither heartless nor paralysed by emotion. Secondly, I now realise that it is not necessary to chastise and rap knuckles. A few weeks after his discharge Steve told me that the thing that frightened him most when he recovered consciousness was what I was going to say. The fact that I made light of it, he said, made him feel more determined to be careful than any telling off could possibly have done. Most people are pretty well aware of having failed to follow instructions or having done something stupid or damaging to their health. The return to the schoolteacher and pupil paradigm, with lines and standing in corners, is only a recipe for truancy.-JOHN $s$ YUDKIN is professor of medicine, University College London

We welcome contributions to fillers: $A$ patient who changed my practice; $A$ paper that changed my practice; $A$ memorable patient; The message I would most like to leave behind, or similar topics. 